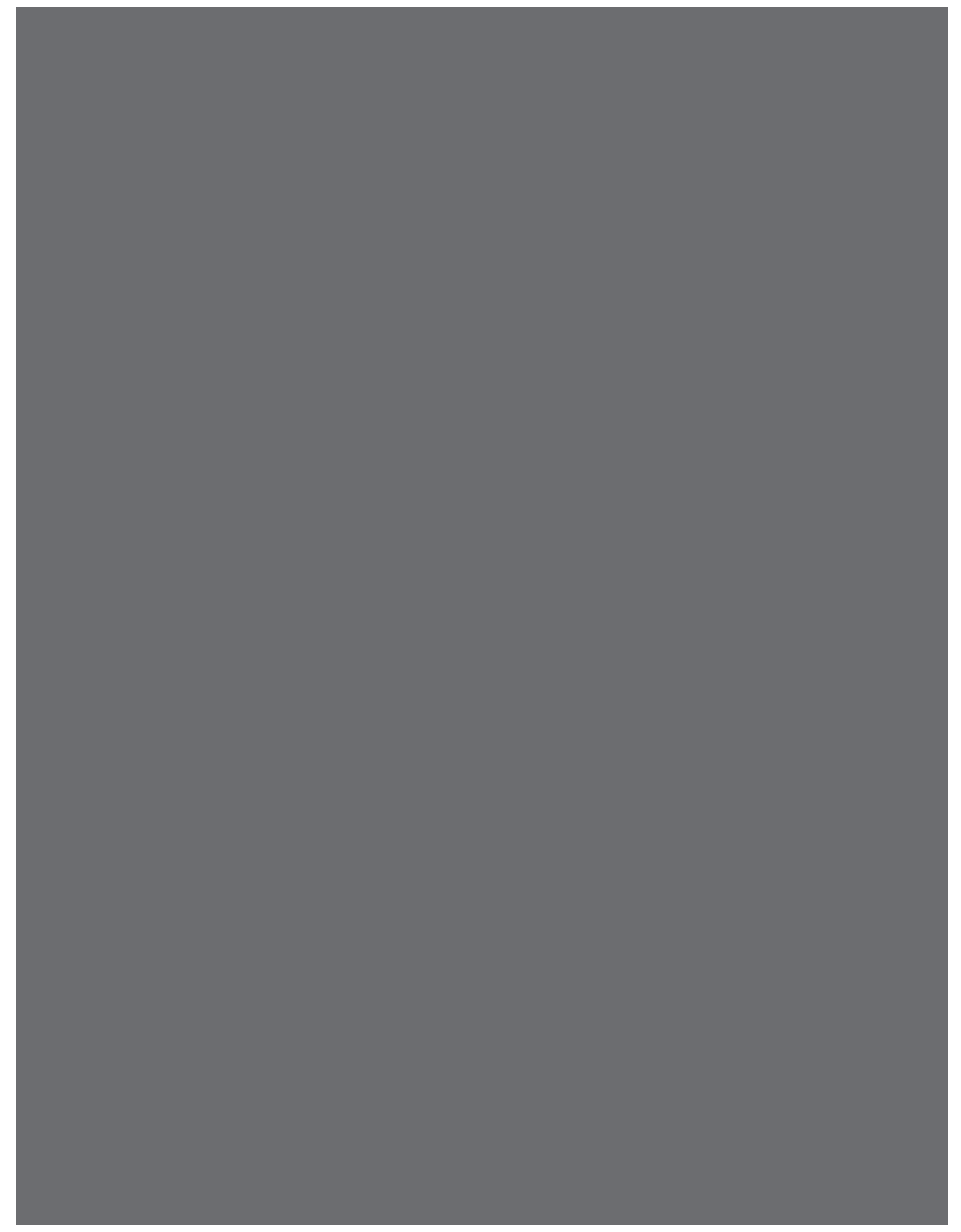




\section{ARTículOS}




\title{
Colombia bajo el imperio de la historia universal. Notas sobre el olvido*
}

\author{
COLOMBIA UNDER THE EMPIRE OF UNIVERSAL HISTORY. NOTES \\ ON FORGETFULNESS \\ COLÔMBIA SOB O DOMIINIO DA HISTÓRIA UNIVERSAL. NOTAS \\ SOBRE O ESQUECIMENTO
}

\section{Miguel Huertas ${ }^{* *}$}

Cuadernos de Música, Artes Visuales y Artes Escénicas

/ Volumen 9 - Número 1 / Enero - Junio de 2014

/ ISSN 1794-6670/ Bogotá, D.C., Colombia / pp. 15-34

Fecha de recepción: 23 de agosto de 2013 | Fecha de aceptación:

20 de septiembre de 2013. Encuentre este artículo en

http://cuadernosmusicayartes.javeriana.edu.co/

doi:10.11144/Javeriana.MAVAE9-1.cbih

* Este artículo forma parte de la investigación adelantada para llevar a cabo la tesis de grado del Doctorado en Arte y Arquitectura de la Universidad Nacional de Colombia.

* Artista plástico, profesor de la Universidad Nacional en la Escuela de Artes Plásticas y la Maestría en Educación Artística. Miembro del grupo de investigación "Unidad de Arte y Educación". 


\section{Resumen}

Lo hagan evidente o no, los discursos institucionalizadores acuden a la historia como la gran legitimadora. Este artículo se refiere a un proceso a través del cual se eligió en Colombia el canon académico para la práctica y la enseñanza del arte; en él podemos observar unas élites altamente ilustradas respecto a las ideas políticas internacionales. Vale decir que -al contrario de lo que muchas veces se ha planteado- la elección de dicho canon no se dio por inercia, ingenuidad o ignorancia de las tendencias más vanguardistas, sino porque respondían a sus intereses de clase. En la base de dicho proceso se halla la historia universal, y la construcción de este canon fue tan eficaz que hoy en día todavía muestra un campo artístico negado a su propio pasado, empeñado en decirse -exactamente como el siglo XIX-que nuestra tradición es la del concierto de las naciones, al cual debemos pertenecer por derecho propio.

Palabras clave: historia; canon académico; enseñanza del arte; academia

Palabras clave descriptores: historia; canón académico; arte-enseñanza; academias; sociedades doctas

\section{Abstract}

Make it clear or not, institutional discourses use history as their great legitimizing force. This article investigates the process through which in Colombia the academic canon for the practice and teaching of art was established. In this process, we see the participation of social elites highly enlightened on international politics. Contrary to what has often been thought, the choice of that canon was not the result of cultural inertia, naivety or ignorance of the avant-garde ideas, but responded to these elites' class interests. At the foundation of this process, universal history was mobilized and the constitution of this canon was so effective that even today it denies its own past and the contingencies of its construction -just as in the nineteenth century that our tradition is that of the concert of nations, to which we belong in our own right.
Keywords: history; academic canon; art education; academy

Keywords plus: history; academic canon; artstudy and teaching; learned institutions and societes

\section{Resumo}

Evidente ou não, os discursos institucionalizadores lançam mão da história como a grande legitimadora. O presente artigo refere-se a um processo a través do qual, na Colômbia foi elegido o cânone acadêmico para a prática e para o ensino da arte; nele podemos olhar umas elites altamente ilustradas no concernente às idéias políticas internacionais, não sobra dizer que -ao contrario daquilo que muitas vezes tem se colocado- o fato de eleger tal cânone não foi por acaso, ingenuidade ou ignorância das tendências mais vanguardistas, mas pelo fato de eles responderem aos seus interesses de classe. Na base deste processo está a História Universal, e, alem disso, a construção deste cânone foi tão eficaz que ainda hoje em dia mostra um campo artístico negado ao seu próprio passado, empenhado em falar -exatamente como o século XIX-que nossa tradição é aquela do concerto das nações, ao qual devemos pertencer por direito próprio.

Palavras-chave: história universal; cânone académico; nação; pedagogía da arte; educação

Palabras-chave descritor: história; taxa

academico; arte - estudo e ensino; academia 
Si en general se reconoce la escasez de estudios sobre las fuentes historiográficas de la historia moderna en Colombia', en el caso de la historia del arte el problema es más agudo. En este artículo propongo una primera revisión de un tema que merece estudios más profundos, no solamente por la luz que arrojaría sobre temas fundacionales de la relación arte y poder en la construcción de un discurso nacional en el siglo XIX -en la cual el problema de la historia es central-, sino, también, por la actualidad de algunas de las preguntas que suscitan estos problemas en el momento actual en los que concepciones aparentemente superadas según la crítica y la historiografía aparecen bajo apariencias contemporáneas como la última novedad. Se notan problemas como el de la enseñanza por imitación de modelos (validados desde el poder), el devenir del "proyecto civilizatorio" que exigiría demostrarnos a nosotros mismos que Colombia es un país a la altura del concierto de las naciones o la misión rectora de las élites a través del cultivo del buen gusto, entre otras.

Este artículo se refiere a un trayecto a través del cual se eligió en Colombia el canon académico para la práctica y la enseñanza del arte. En él podemos observar unas élites altamente ilustradas respecto a las ideas políticas internacionales; vale decir que -al contrario de lo que muchas veces se ha planteado- la elección de dicho canon no se dio por inercia, ingenuidad o ignorancia de las tendencias más vanguardistas, sino porque respondían a sus intereses de clase. A este respecto, habría que señalar -aunque no sea éste el sitio en el que se podría argumentar en detalle al respecto- que, a pesar de sus reales y evidentes diferencias políticas (bastaría señalar como confirmación de ellas la inusitada cantidad de guerras civiles que sacudió la naciente República de Colombia), existió un proyecto común en las élites, que ha sido denominado el proyecto civilizatorio y, aunque insuficientemente caracterizado aún, todavía tiene una gran fuerza.

En este trayecto ocupó un lugar muy importante José Manuel Groot (1800-1878), cuyos distintos campos de acción reflejan muy bien el amplio y problemático panorama del país y del mundo occidental. Estos campos abarcan muy significativamente sus diferentes facetas: la historia (con una obra tan importante como la Historia civil y eclesiástica de la Nueva Granada), la historia del arte (con su obra fundacional Noticia biográfica de Gregorio Vasquez Arce i Ceballos. Pintor granadino del siglo XVII con la descripcion de algunos cuadros suyos en que mas se da a conocer el mérito del artista), la de pedagogo (fundó la "Tercera escuela de educación de alumnos internos pensionistas", 1828), la de polemista católico (en la que en medio de numerosos artículos y libros se destaca la Refutación analítica del libro Mr. Ernesto Renan, titulado Vida de Jesús, 1865), además de la de escritor de costumbres, pintor costumbrista y caricaturista.

De la complejidad de su mundo y del mundo que le correspondió vivir habla esta prolífica producción. La demostración de que esta condición, que en ocasiones llega a ser contradictoria, no era personal está dada por la actualidad de la discusión de Walter Benjamin, que sitúa en el siglo XIX el centro de las fantasmagorías de la modernidad², cuyo centro es, precisamente, las nociones de historia y particularmente el modelo de historia de la civilización o historia universal. 


\section{DOS IMÁGENES}

Casi 30 años antes de la fundación de la Escuela Nacional de Bellas Artes, José Manuel Groot ponía ya en términos claros una conciencia de que había por lo menos dos cánones posibles para el arte nacional: uno, que él mismo cultivaba, tendía a la fidelidad de la representación del natural, particularmente de las costumbres populares, y el otro, que buscaba la belleza, representado (aunque no lo nombre directamente así) por el modelo academicista ${ }^{3}$. Dos documentos nos hablan de ello, el primero un poema de 1858 :

\author{
Un cuadro quiero pintar \\ En que represente al vivo \\ Las costumbres y maneras \\ Del rústico campesino. \\ Costumbres con su lenguaje, \\ No de la clase del rico. \\ Que no pinto sino al pobre \\ Con sus modales y dichos.
}

No tomaré los colores

De la paleta de Guido,

Ni tampoco del Ticiano,

Pues la belleza no pinto!

Aunque el pintar la belleza

Es asunto relativo

Si por belleza entendemos

Pintar bien lo que se ha visto,

Dando a cada personaje

Y a cada objeto su tipo,

Su carácter natural

Con su genio y sus caprichos.

Los cuadros de Van Ostade

$Y$ de Teniers son divinos;

$Y$ representan asuntos

De populares estilos.

La belleza angelical

Pintaba Rafael de Urbino;

Y la belleza en un rato

Representaba Murillo. 
En mis cuadros no pretendo

Hacer tanto, y sólo pido

Se compare al natural

Para juzgar lo que pinto.

Y por eso este romance

A un conocedor dedico

Que tiene gusto en pintura,

Es poeta y es mi amigo. (Groot, 1991)

Con toda claridad-ejemplos incluidos-, Groot reconoce estos ámbitos, así como en sus escritos históricos demostró un gran conocimiento de los autores que generaban debate en la Europa de su tiempo 4 .

El segundo documento es la Noticia biográfica de Gregorio Vasquez Arce i Ceballos. Pintor granadino del siglo XVII con la descripcion de algunos cuadros suyos en que mas se da a conocer el mérito del artista (1859), la obra inaugural de la historia del arte en Colombia, que apunta directamente hacia el género de la historia universal, base del pensamiento académico que se adoptó como modelo para la Escuela Nacional de Bellas Artes de Colombia. Lo significativo es que, a pesar de ser él uno de los pintores y escritores importantes del país con su lenguaje costumbrista, en su estudio de Vásquez centra su defensa de la genialidad del olvidado pintor colonial en su estrecha correspondencia con los valores de la academia ${ }^{5}$.

Groot, que en su niñez vivió el influjo de la Expedición Botánica, en su juventud el del liberalismo y la masonería y en su época adulta el del conservatismo, apologista del catolicismo, revela una gran lucidez respecto al mundo en que vive (a pesar de no haber realizado el viaje ritual a Europa) y a la decisión de afiliarse al proyecto conservador de nación llamado La Regeneración.

La segunda imagen podría parecer forzada, pero no creo que lo sea. Muestra la complejidad del espacio de resonancia de los conceptos de historia en el siglo XIX en que Colombia se situaba, y surge de la puesta en relación de varias obras cuya construcción coincidió en un momento dado: en el año 1851 (el mismo de la realización de la Primera Exposición Universal en Londres) salía a la luz el primer volumen de la primera enciclopedia escrita en español: la Enciclopedia moderna - Diccionario universal de literatura, ciencias, artes, agricultura, industria y comercio, dirigida y editada por Francisco de Paula Mellado, con la promesa de concluir su edición (que se adquiría por suscripción) en dos años. En diciembre de ese mismo año ocurría en Francia el golpe de estado de Luis Bonaparte, quien se coronó como el emperador Napoleón III, lo que suscitaría la casi inmediata publicación (también pensada originalmente para publicar por entregas en una revista norteamericana a partir del primero de enero de 1852) del sobrecogedor ensayo de Karl Marx El dieciocho brumario de Luis Bonaparte. En este -siguiendo a su autor- las nociones tradicionales de historia estallan al comprobar su incapacidad para comprender, sin pensar que fuera una absoluta excepción, cómo un personaje mediocre pudiera haber dado un golpe que tomó por sorpresa a todos, "un rayo que cayese de un cielo sereno" (1976, p. 412). Marx -en sus propias palabras- demuestra que, muy al contario, la lucha de clases había creado en Francia las circunstancias para que dicho personaje pudiera representar el papel de héroe ${ }^{6}$. Igualmente, por estos años, ya José Manuel Groot trabajaba en la Nueva Granada en la Noticia biográfica, obra fundacional de la historia del arte colombiano, que finalmente se publicaría en $1859^{7}$. 


\section{VISIONES DE LA HISTORIA}

Groot es muy consciente en su deseo de hacer una historia diferente a la que se hizo en época de Vásquez, del cual sólo encuentra una referencia en "el padre Zamora, que escribía en 1669 (...) en un pais sin establecimientos científicos que trasmitan de una edad a otra los anales del saber" (Groot, 1859, p. 2) ${ }^{8}$. Por esta razón, su investigación se nutre de archivos y entrevistas:

Las noticias de que se compone esta biografía son tradicionales (...) porque los cronistas antiguos de nuestro pais parece que no escribian para la posteridad sino para sus contemporáneos, a quienes suponian impuestos de lo presente. (Groot, 1859, p. 2)

Él, en cambio, sabe que se escribe la historia para el futuro: “El deseo de que no se pierda para mi país la memoria de un artista célebre cuando tan escasos han sido nuestros progresos en las bellas artes."Tal como lo dijera Heródoto:

Esta es la exposición de las investigaciones de Heródoto de Halicarnaso, para que no se desvanezcan con el tiempo los hechos de los hombres, y para que no queden sin gloria grandes y maravillosas obras, así de los griegos como de los bárbaros, y, sobre todo, la causa por la que se hicieron guerra9. (Groot, 1859, p. I)

Y Vasari:

(...) que no es [mi intención] la de ganarme alabanzas como escritor sino, como artífice, la de alabar el ingenio y avivar la memoria de aquellos que, habiendo dado vida y ornamento a estas profesiones, no merecen que sus nombres y sus obras sean, como lo eran, fácil presa del olvido o de la muerte. (1996, p. 22)

Volveremos más adelante sobre las referencias históricas de la Noticia biográfica.

\section{LA MODERNIDAD DE LA ENCICLOPEDIA}

Si bien la Enciclopedia moderna (Mellado, 1851) no tiene una definición de modernidad"10, es ella misma un anuncio de "una nueva era" de la civilización:

La publicación de la Enciclopedia Moderna no es mas que el complemento de un plan general al que están subordinadas todas mis empresas literarias: en ellas he querido siempre hermanar mis intereses con los del pais, porque juzgo un deber imprescindible el que cada uno contribuya en su esfera á levantar el gran edificio de la civilización; obra de suyo difícil y penosa de que por desgracia apenas se han echado todavía en España los cimientos (...) en este siglo las obras enciclopédicas son de absoluta necesidad, por los progresos de la cultura, por la tendencia de las ideas y hasta por la organización política de la mayoría de las naciones. 
Estamos ante un proyecto político ilustrado, moderno y nacional. La Enciclopedia moderna no se limita a ser un compendio de conocimientos más o menos conectados, sino que traza un panorama general del conocimiento posible y de la estructura del mundo y de su historia, lo que debería tener profundos efectos en la vida social; además, su forma de distribución propone la ruptura del monopolio en la adquisición y circulación del saber, ampliándolo a "la masa".

Junto a estas intenciones, digamos progresistas, menciona la importancia de la historia sagrada y propone a Dios como principio general. Está muy marcada por un carácter evolucionista que lógicamente sitúa en la cúspide a la modernidad, cuya forma más alta advendrá en el futuro.

\section{EL TRIBUNAL DE LA HISTORIA}

Una de las bases, no siempre visible, sobre la que se construyen los modos de legitimación social es la concepción de la historia; en las formas como la sociedad define su pasado y las relaciones que con él se tejen, se construye también una tradición y una aspiración a la posteridad. Esta es el espacio por conquistar, la preservación del recuerdo es la tarea y la guía del futuro es la recompensa.

En el rastreo de este tipo de obras hemos encontrado entre 1820 y 1860 (fechas dadas por la organicidad de la investigación, no porque definan un periodo) toda una legión de historias universales, geografías universales, diccionarios universales, todos ellos suma exhaustiva de un saber. Eso sin mencionar el establecimiento de las exposiciones universales, la primera de ellas The Great Exhibition de Londres en 1851, que muy poco tiempo después fue reproducida en Francia y se estableció como un modelo que hoy en día todavía existe, al igual que el género historia universal"1".

Uno de los grandes referentes de ese género es Jacques B. Bossuet ${ }^{12}$, quien es citado no solamente en obras francesas y españolas de la época, sino también con mucha frecuencia por autores colombianos como Groot ${ }^{13}$. El texto clásico de Bossuet es Discurso sobre la historia universal, y abre una de las obras de dicho género en español, Los héroes y las grandezas de la tierra, en la cual Manuel Ortiz de la Vega (1856), su autor, plantea una discusión contra la filosofía de la historia:

El verdadero filósofo de la historia, el más consolador al menos de todos ellos, es Bossuet el grande, en su discurso sobre la historia universal. Fuera de él no veo en la filosofía de la historia más que el caos. (1856, p. I)

Así como en la Noticia biográfica nos muestra Groot su desacuerdo con la falta de fe de los "pintores modernos", en Los héroes y las grandezas de la tierra de Manuel Ortiz de la Vega (1856) no toda referencia a la modernidad es celebradora; con frecuencia se reconocen rasgos de degradación de la existencia, que desembocan directamente en una nostalgia por el pasado idealizado. En relación con el aparte de historia encontramos:

Hay dos maneras de escribir la historia; la una siendo los que la escriben meros historiadores, es decir hombres imparciales que instruyen con conciencia y claridad una especie de proceso de la época que se han propuesto examinar, y ponen á la vista lodos los documentos que pue- 
den conducir á arrojar luz sobre los hombres y las cosas tocantes á la misma: en cuyo caso el lector no ha de hacer otra cosa que fallar según su juicio en acabando de leer, ó bien pedir á otros historiadores nuevos datos si no le parecen suficientes los que tiene delante para poder fundar su fallo. La otra manera de escribir los anales de los pueblos es aquella en la cual el historiador enarra y juzga, arregla el proceso á su manera y falla según sus opiniones, elige el punto de vista que más le cuadra para medir á los héroes y á los pueblos, ensalza ó derriba, realza ó encubre, baja ó sube, siempre con mucho arte y mafia, los hechos y las cosas que favorecen ó contrarían su modo de ver y de juzgar en legislación, en moral, en culto, ó en política. Los primeros tratan de explicar pocas cosas, antes desean que el lector se las explique. Los segundos lo explican todo, hasta las causas de las minuciosidades, y no quieren que el lector se tome el menor trabajo. Los benedictinos pertenecen á la primera escuela; los cronistas, y varios muy respetables historiadores siguen el mismo rumbo. No así la escuela moderna. El lector ha de enmudecer delante de ella, y se ha de limitar á creer ó arrojar el libro. Afortunadamente el tono magistral, decisivo, y sentencioso del escritor, ponen desde luego en guarda á los lectores. Pero algunas veces el escritor de talento, si sabe manejar bien la pluma, viste con las apariencias de un estilo hermoso, elocuente, y artísticamente trabajado, sus pensamientos culminantes, y hace de esta suerte que los paladee con gusto el lector que de otra suerte los hubiera rechazado: estos son los historiadores más peligrosos, y por esto decia un antiguo que prefería mil veces que su virtud tuviese que luchar con toda la desnudez de una cortesana, que con la modestia y los embelesos engañosos de una hipocresía disfrazada. En estos casos el lector solo se puede guiar por el humo de la vanidad que difícilmente puede ocultarse. (Ortiz de la Vega, 1856, p. 41)

En esta misma obra se define la historia:

Émula del tiempo, depósito de las acciones, testigo de lo pasado, ejemplo y aviso de lo presente, y advertencia de lo porvenir ${ }^{14}$, llama el Inmortal Cervantes á la historia, sin cuyo estudio no hay mas que degradación y miseria del espíritu, y con el cual hay verdadera sabiduría fundada en la experiencia de los siglos.

Pero no es muy fácil el dar satisfaccion á esa universal necesidad de conocer todo cuanto en el mundo ha pasado desde que salió de las manos del Hacedor hasta nuestros días; á saber, la marcha de las sociedades, los adelantos en las ciencias y en las artes, los progresos de la civilizacion, la formacion, el engrandecimiento, las convulsiones y la ruina de los Imperios (...) Chateaubriand: "Poseo muchas historias universales y ninguna me sirve; en todas mis dudas ningún libro me da luz fuera de la obra maestra de los benedictinos. Cuando no tengo á la mano este libro hago cuenta que me faltan todos (...) De eso sabios modestos, añade en otro lugar, á quienes cupo la triple gloria de dar la Europa al arado, de cristianizarla y de escribir y de archivar sus anales." Y lo mismo están repitiendo los hombres eminentes de todas las naciones, afirmando á una voz que sin aquella obra ninguna biblioteca es buena, y que ella sola basta para formar una. (...) Cuando las mas grandes naciones del mundo se creen llamadas á apoyar sobre el hierro lo que llaman su derecho, el genio de la historia extiendo sus alas, se remonta, evoca lo pasado para explicar lo presente, y hace oir sus fatídicos acentos. Pasó el tiempo en que pudo decirse impunemente que nuestra sociedad, poco profunda para la historia, solo era digna de leer novelas: ya las novelas han de denominarse históricas para encontrar lectores, 
porque la bistorta, antorcha que ilumina el ingenio, es la reina del mundo. Y la obra preciosa de los benedictinos no se parece en nada á esas historias en que no se enarra, sino que se discute, y no se da enseñamiento al espíritu sino irritacion á las malas pasiones; no es como aquellos torrentes que en vez de dar vida á los campos siembran en ellos la destruccion y la ruína: es una corriente majestuosa, vivificadora y cristalina. (Ortiz de la Vega, 1856, p. I)

Otro gran referente de Groot es Cesare Cantú (1807-1895) (Cantú, 1854). Sobre él nos informa el prologuista de la traducción española de la Historia universal, editada por Gaspar y Roig:

Al aparecer en Europa las primeras entregas dé la Historia Universal escrita por César Cantú no pocos literatos de nombradía experimentaron cierta desconfianza hacia su autor, sospechando que no podría dar cima á una obra tan vasta, superior á las fuerzas ordinarias de un hombre. Las grandes tradiciones de san Agustín y los trabajos de Bossuet y de Vico ofrecieron la idea de un nuevo modo de escribir la Historia, la cual no se miraba ya como un conjunto de hechos sin conexión ni enlace sino como un todo homogéneo, cuyas partes, armónicamente unidas, contribuían á la investigación de los altos destinos de la humanidad y al descubrimiento de las leyes morales que presiden á su desarrollo en la serie de los tiempos El autor de una obra tan vasta desempeñada con arreglo á este plan de tan inmensas proporciones, debía reunir á la paciencia investigadora de un Benedictino el ardor incansable de un Enciclopedista; y no se creía por algunos que César Cantú, joven todavía, estuviese "adornado" de estas cualidades. Mas de diez años han pasado desde entonces, y las muchas ediciones que han seguido sin interrupción á la primera, y la fama de que toda Europa ha cubierto el nombre del autor prueban que ha sabido realizar la idea que en nuestro siglo se tiene de la Historia.

En efecto lo que Bossuet hizo respecto de los sucesos capitales que eligió en el vasto campo histórico, según convenía á su gran propósito de señalar en la elevación y caída de los imperios la mano de la Providencia, César Cantú lo ha practicado respecto de todos los hechos en su conjunto y en sus pormenores en sus causas y en sus resultados. En el curso de los siglos distingue el Progreso como ley constante de la humanidad siguiendo el desarrollo que el dedo de la Providencia le marca; progreso que se realiza á pesar de los desastres, al través de las dificultades y aun en medio de los yerros de la raza humana. (Cantú, 1854, p. XV)

Ya en el comienzo de su impresionante obra el propio Cantú hace un Discurso sobre la historia universal, al que remitimos directamente al lector. Este texto es relativamente extenso, denso en referencias, y constituye un muy interesante campo de análisis que desborda este estudio y del cual sólo haremos algunas cortas citaciones para mostrar la continuidad de todo un género moderno ${ }^{15}$ con el que se identificarán muy fluidamente muchas de las manifestaciones intelectuales del final de siglo en medio de las cuales se situará la creación de la Escuela Nacional de Bellas Artes de Colombia:

Ninguna ciencia satisface tan completamente como la Historia la inmensa necesidad de lo verdadero, de lo bello, y de lo bueno que la humanidad siente mas imperiosamente á medida que mas adelanta en su camino. Nuevos nosotros en este mundo y sucesores de aquellos que conociéndolo apenas, lo abandonaron; anillos temporales de la cadena en la cual, á pesar de la destrucción de los individuos, se perpetúa la especie, ¿cómo podríamos dirigirnos si estuviéramos atenidos solamente a la propia experiencia? En poco superiores á los brutos, y acaso mas desgraciados 
que ellos; guiados por el instinto del placer ó el imperio de la necesidad, nos pareceríamos al niño nacido á media noche, que al ver salir el sol, lo creyera acabado de crear en aquel momento. (p. XV)

Cantú define a su manera el oficio del historiador:

Pero si se limita [la historia] á una vasta colección de hechos, de los cuales pretende el hombre deducir norma para obrar en circunstancias semejantes, serán insuficientes é inútiles sus lecciones, porque nunca se reproducen los sucesos con iguales accidentes. Mas alta importancia cuando considera los hechos como una palabra sucesiva, que mas ó menos claramente manifiesta los mandatos de la Providencia; los enlaza no con la idea de utilidad parcial, sino con una ley eterna de caridad y de justicia; cuando no se contenta con descubrir, envenenar y contemplar tristemente las llagas sociales, sino que hace que los dolores sufridos por los antepasados, y las lecciones de las grandes desventuras redunden en provecho de las venideras. Entonces nos eleva sobre intereses efímeros y mostrando que somos miembros una asociación universal que se dirige á la conquista de la virtud, de la doctrina, de la felicidad, dilata nuestra existencia á todos los siglos, nuestra patria á todo el mundo, nos hace contemporáneos de los grandes personajes y nos manifiesta la necesidad de dejar con aumentos á nuestros sucesores la herencia que de nuestros padres recibimos (...). (1854, p. XV)

Cantú también define su objetividad: su relato se convierte en una especie de tribunal en el que el oficiante juzga y ejecuta a nombre de la historia ${ }^{16}$, el tribunal del tiempo:

El historiador es un testigo que declara la verdad de los sucesos, con vigorosa imparcialidad con la buena fe que caracteriza al hombre de honor; pero al mismo tiempo es juez, que tiene opiniones propias sobre aquellos hechos, los aprueba ó condena, provoca con las suyas las reflexiones del lector, y lo encamina á esa instrucción moral y social que debe deducirse cada página de su libro. En este segundo oficio puede engañarse y ser reprobado; pero le servirá siempre de excusa la buena fe que empleó en la libre manifestación de sus juicios, y el haber distinguido la enunciación de los acontecimientos positivos de las conjeturas que anticipadamente hizo relativas á ellos. (1854, p. L)

\section{EL MUSEO UNIVERSAL, MODELO PARA LA NOTICIA BIOGRÁFICA}

Volviendo a las fuentes de la Noticia biográfica, así no contenga imágenes -situación que podemos atribuir a la falta de una base técnica (aunque ya desde 1848 Manuel Ancízar había abierto una litografía "con los mayores adelantos modernos", se trata no solamente de la posibilidad de imprimir, sino del desarrollo de un lenguaje de traducción de las complejas imágenes pictóricas a grabados monocromos y de fácil reproducción, lo que se logró con la técnica llamada grabado de contorno)-, la mención que hace Groot y la comparación de sus textos permite pensar que el Museo universal fue en buena medida uno de los modelos que tuvo para la redacción de su Noticia biográfica.

Veamos el Museo universal, en el que la descripción es al mismo tiempo valoración y juicio estético y moral:

La parábola del hijo pródigo es acaso la mas tierna y hermosa del nuevo testamento (...) A pesar de que con figuras de medio cuerpo no sea facil representar una verdadera eomposicion 
histórica, sin embargo Leon Spada ha sabido pintarnos muy bien aquella admirable escena del Evangelio en un cuadro que es una de sus mas bellas obras.

La espresion del hijo pródigo es admirable, y uno cree estar oyendo sus palabras:

«Padre mio, he pecado contra el ciclo y contra vos.»

El colorido de esta figura está lleno de vigor y de verdad; los brazos están diseñados y pintados con grande perfeccion; el lienzo es ligero y gracioso, y el tono general del cuadro sobremanera armonioso. La accion del padre está llena de sentimiento: apresúrase á cubrir con su manto de púrpura la desnudez de su hijo, y le perdona con el alma todas sus faltas.

La cabeza del anciano presenta un caracter grandioso, el ojo casi cerrado espresa muy bien su enternecimiento, asi como su rostro la compasion y el amor, y el de su hijo el arrepentimiento y la esperanza.

Este cuadro ha sido grabado por Fossoyeux.

Tiene de alto 4 pies con tres pulgadas, y de ancho 3 con ocho. (Verdaguer, 1840, p. 64)

En la Noticia descriptiva de algunos cuadros de Vásquez (Groot, 1859, p.14 y sts), Groot recurre al mismo principio descriptivo que, a falta de imágenes visuales, se enriquece con el talento narrativo del escritor:

El cuadro de Santo Domingo revistiéndose tiene dos varas i media de alto i dos de ancho; las figuras son del tamaño natural. El Santo tiene puesta el alba, e hincado en una grada recibe la estola de manos de la Virgen que está de pie, i detras hay unas nubes luminosas que descienden de arriba con unos anjelitos. Detras de Santo Domingo está hincado un corista apuntándose el síngulo que le ha ceñido. Vásquez incurrió en el defecto de introducir dos escenas en esta composicion; aunque bien se le puede perdonar por la bella ejecucion de la segunda; en que puso al santo en término mas lejano diciendo misa en el altar, i al corista ayudándole. Esto se ve a toda luz en la parte de afuera por entre una puerta que está en el fondo del cuadro.

El dibujo es mui correcto: las actitudes fáciles i graciosas...

Las carnes de la Vírjen son puras i virjinales; las manos mui bien dibujadas i la fisonomía del rostro es lo mismo que todas las de las vírjenes de Vasquez, que en viendo una pueden darse por vistas todas, porque todas son hermosos i de igual tipo.

La cabeza del santo es exelente; de un colorido fresco í jugoso; llena de candor i mansedumbre su espresion es bondadosa, noble i devota: recibe con amoroso respeto la estola que representa la santa Virjen: la actitud es mui natural: el dibujo mui correcto, i el claroscuro, dado en masa, es magnífico. Como la luz fuerte viene del resplandor celestial que trae la Vírjen i hiere de frente al Santo, el cuerpo de este produce una columna de sombra hácia atras; por consiguiente, el corista que está apuntando el síngulo, queda comprendido bajo esta masa de sombra; pero como a Vasquez le gustaban tanto los accidentes de luz, i los sabia disponer con tanto acierto como gracia, dió al corista la actitud mas natural i la espresion mas adecuada para figurarlo apuntando con gran cuidado el síngulo, en cuya operación inclina un poco la postura, y alcanzando a sacar un poco la cabeza fuera de la sombra, le pasa un rayo tangente de luz por la parte superior de la frente que se ve alumbrada como si le diera la luz del sol (...). (1951, 38-39)

En el siglo XIX, un cuadro es todavía una aparición impactante, capaz de influir en los comportamientos, incluso de educar por su sola presencia, que no acontecía en cualquier parte: 
aparte de las iglesias y algunos lugares institucionales, el contacto con obras de envergadura era algo inusual. Sin embargo, su poder comunicativo y educativo dependía de que fueran vistas y no solamente de manera incidental, sino sistemáticamente, paradoja que plantea el Museo universal: "¿Cómo, pues, esas obras, que son tan populares, no se han popularizado todavía?" (Verdaguer, 1840, p. 2).

\section{LA PROPAGANDA DE LAS COLECCIONES Y LA SOCIEDAD EDUCADORA}

Publicaciones como el Museo universal cumplen una serie de roles fundamentales; por un lado, difunden las obras plásticas para un público más amplio, que genera la democratización del disfrute de estas y, del otro, educan al público, ya que suavizar sus costumbres y hacer retroceder la barbarie era una necesidad política para las élites (Matilla, 2000)17.

Pero sus efectos no se detienen allí, la publicación de las obras plásticas en colecciones implica, más que una reproducción, una traducción, cuyo efecto es el de sesgar las imágenes a través de una carga literaria, que apunta a una nueva relación entre artes plásticas y literatura. El Museo universal describe muy claramente esta novedad en su introducción: si hasta el momento era lo común que las primeras ilustraran la literatura, ahora esta última se ponía al servicio de la explicación de las primeras. Esta carga literaria y pedagógica -a la que no es en absoluto ajena la obra de arte actual- define un tránsito muy importante en la percepción de las obras plásticas: el paso de la pintura de historia a las pinturas que cuentan historias.

\section{LA HISTORIA, EL GÉNERO DE LA ACADEMIA}

Es importante recordar en este punto que el género por excelencia de academia era la historia. Es muy común suponer que la pintura y la escultura académicas se reducen a jarrones, cortinas, retratos de sociedad y mujeres desnudas, pero no es así. Desde la formación inicial hasta la temática de los grandes concursos profesionales, todo el lenguaje académico es un discurso sobre la historia estricta y detalladamente normatizado ${ }^{18}$; así, al tiempo que las obras están realizando una labor de divulgación, por la misma vía modelan el gusto de la sociedad, lo que contribuye a asentar valores, modos de ver y, como dice Matilla, mentalidades.

Con estas notas, intentamos describir a muy grandes rasgos, el contexto contemporáneo que Groot cita y cuyas contradicciones internas se reflejan muy bien en el Museo universal, ejemplo del pensamiento ilustrado, liberal y moderno que intenta llevar los más refinados logros del conocimiento a todas partes, pero que no logra desprenderse del pasado, condición moderna sine qua non ${ }^{19}$. A falta de esto, la cultura queda extraviada entre las imágenes del progreso más reciente y el pasado inmemorial que envuelve la experiencia en un ámbito de fantasmagorías, como lo describirá en el siguiente siglo Walter Benjamin ${ }^{20}$.

Así como es un error considerar la academia como lo opuesto a modernidad, también lo es considerar que la historia universal se opone a la voluntad de ser modernos. Entendida como la constitución de un campo disciplinar autónomo, fue la academia la que configuró la modernidad del arte. Apartándonos totalmente de alguna visión nostálgica de los valores académicos (por demás, dogmáticos, autoritarios y discriminatorios), es necesario reconocer esta lucha que atraviesa toda Europa a partir del siglo XVII y se refleja en la Colombia del siglo XIX, cuando se nombra al arte como actividad profesional autónoma. 
En cuanto a la historia universal, aunque describamos como conservadora su ideología, debemos reconocer inscrita en ella la voluntad de estos hombres ${ }^{21}$ de ser modernos. Dicho conservadurismo permea todas las creaciones que en ella se basan y que en términos generales se asocian con lo que denominamos "proyecto civilizatorio", adoptado como discurso nacional y que convenía a las élites en el poder para legitimarse como un fuerza histórica, progresista y moderna.

\section{EL PROBLEMA DE LA HISTORIA EN LA ESCUELA}

Con variantes locales, la historia que se reconstruye aquí probablemente no difiere en lo esencial de la de otras escuelas colombianas, y es una historia que se seguirá repitiendo en tanto no se comprenda más profundamente la naturaleza de sus fantasmagorías y se definan mejor los pensamientos concretos que originalmente estaban detrás de ellas; es decir, en tanto un esfuerzo colectivo no decida dejar conscientemente el siglo XIX atrás. Es necesario saber contra qué se lucha, las poderosas fuerzas que vienen de un pasado que aún nos permanece oscuro y, sin embargo, reproducimos. Avanzando en la investigación, se fue haciendo evidente lo poco que sabemos de la "academia" como hecho histórico concreto: cada quien tiene una idea propia y a ella se remite; esas ideas personales son más o menos parecidas a otras ideas y todas en conjunto parecen remitirse a los mismos tópicos que -frente al análisis- no pasan de ser generalizaciones difusas, como su condena por reducirse a la supuesta realización de "manualidades".

La historia universal, que hace un recuento del progreso de la humanidad hacia la civilización como un destino inevitable, yace en el origen de los discursos que en el siglo XIX fundaron la Escuela Nacional de Bellas Artes. Esta historia, que mezcla mitos creadores con crónicas de los hechos verdaderos para construir un pasado útil que surta los modelos en los que se deposite toda la autoridad, exige el apego a formas establecidas que coinciden exactamente con los intereses de las élites que tienen el poder y define la calidad de las obras de arte. El profesor, elegido por su coherencia con el sistema, dictamina sobre la capacidad del alumno para prolongarlo; su autoridad se define por su éxito en innumerables concursos -de ingreso a la Escuela, de estudios, de acceso a los salones, de obtención de contratos oficiales y de reconocimiento de la academia- y ejerce su acción correctiva como un agente del tribunal de la historia.

El profesor de artes colombiano a finales del siglo XIX tiende a situarse en el espacio abierto por la llegada de la civilización europea, con la que se siente totalmente conectado y participa de la construcción del panteón nacional. Pautada su acción como artista y como profesor por las fechas de significación patriótica, definidos sus modelos por las personalidades de las élites y garante de la moral católica, tiene muy poco campo de acción para construir otros modelos. La vanguardia le es impensable y cuando llegue, de la mano de Andrés de Santa María, será bajo el anuncio de la novedad estilística y no de una reacción que pretenda cortar con un presente insatisfactorio, prestando su ropaje de algún pasado ennoblecido que no puede surgir de relatos que aún hoy permanecen silenciados.

Tal como su enseñanza, también la historia del arte fue en principio asunto de artistas. Groot y Pizano hicieron las obras de más largo aliento en mucho tiempo, ambos trabajando con la figura canónica de Vásquez y Ceballos; Acuña, que llegó a ser miembro de la Academia 
Colombiana de Historia, amplió el rango de investigaciones hacia las manifestaciones populares y participó en la redacción de la Historia extensa de Colombia y se constituyó en el representante más característico del indigenismo, manifestación conservadora e ilusoria que en vez de hacer visible lo indígena lo ocultó22. Evidentemente, otros intelectuales aportaron a la construcción de una historia del arte colombiano y ni de unos ni otros hay estudios específicos sobre sus fuentes historiográficas.

Hay otra línea menos evidente y también muy problemática: el hacer del arte tiene una historicidad inherente $y$, siguiendo a Argan, podemos asumir que una obra de arte siempre implica un comentario al trabajo humano, a la vez que implica uno a la historia. Así, la enseñanza del arte en cualquiera de sus detalles glosa las maneras como su objeto ha sido históricamente definido y, en últimas se apoya en, o genera, una definición de historia.

El sistema académico lo sabía, y una de sus condiciones era no perder de vista nunca su compromiso con la historia; las vanguardias lo sabían y ponían en primera fila de la visibilidad su historicidad (yendo muy frecuentemente a contrapelo de la historia oficial). Sin embargo, en la cotidianidad de las escuelas colombianas de arte -sean cuales sean sus enfoques- uno de los peligros que acechan tras la costumbre y el acumulamiento de certezas es el de olvidar esa condición estructural. Por eso, es muy frecuente encontrarnos en los discursos pedagógicos del arte una linealidad histórica que pareciera dirigirse, directo como una flecha, al momento actual, cima máxima del progreso en el pensamiento del arte, lo que permite cancelar el pasado y borrar la memoria histórica.

Teóricamente, en las escuelas modernas el taller, antes que acumular certezas, se esfuerza por construir una tensión crítica y por mantener la voluntad de no superarla, ya no se espera conservar una idea conclusa y reglamentada de la historia, sino sostenerse en un lugar en donde, de vuelta siempre al origen, se plantea nuevamente la pregunta sobre la construcción de sentido.

Sin embargo, a pesar de ser tan importante este punto, en general el profesor de artes no tiene una formación mínima en problemas historiográficos que le permita comprender su profundidad y extensión. En consecuencia, la lógica de los cambios tiende a diluirse y a considerarlos solamente como una deseable y periódica actualización estilística.

Las reformas de las escuelas de arte de la última década del siglo $X X^{23}$ recuperaron la centralidad del problema de la historia. Conscientemente se proclamó que ella hacía parte de los insumos de la discusión en los talleres; con ello se superaría la compartimentación entre asignaturas teóricas y prácticas: la historia no era asunto particular de algunos lugares especializados, aparecía en todos ellos. Sin embargo, el debate apenas quedó esbozado, y la escisión -en la medida en que la discusión historiográfica no se generalizó- no se resolvió, aunque quedara en el aire la impresión de que una nueva concepción de la historia se había instalado.

Revisar el contexto institucional que legitima las obras y los artistas les devuelve una sustancia que normalmente no se ha tenido en cuenta en la historiografía convencional. Una de las características del canon académico es que el mismo sistema de autoridades que nombraba a los artistas exitosos como profesores de la escuela determinaba qué clase de obras debían hacerse, intervenía en los concursos que las premiaban y, por lo tanto, incidía estructuralmente en la decisión de qué artistas tenían éxito.

Esta función del sistema, que tiende a perpetuarse a sí mismo, sólo es comprensible estudiando la historia de las instituciones: los sistemas no se crean ni se reproducen solos, son el resultado de decisiones y de acciones de personas concretas, puestas en lugares 
concretos y con intereses concretos en un movimiento que desborda la voluntad e, incluso, la conciencia de los individuos, aunque sean éstos los que las transforman o las estatizan por acción u omisión.

Una historia del arte colombiano que renuncie a las mistificaciones revelaría el complejo entramado institucional que rodea sus acontecimientos, que no son en nada gratuitos ni derivados de una ingenua o malintencionada ignorancia respecto al poder del hecho artístico. No es necesario continuar con la idea de que hay que alfabetizar a las élites en el poder y que, comprendiendo éstas el alto valor del arte, actuarían más responsablemente respecto a su apoyo y divulgación y a la conservación del patrimonio. Las élites también trabajan para su propia perpetuación y una de sus mejores armas ha sido la manipulación del gusto, a través de la cual han instalado sus valores como verdad natural: así, la persecución de modelos adecuados sigue siendo desde el siglo XIX el propósito privilegiado de las escuelas de artes; siendo indiferente si el modelo es academicista, modernista o posmodernista, el objetivo es mantener una delgada zona en la que se garantiza la continuidad de un pensamiento subordinado, que al mismo tiempo se autorrepresenta como perteneciente al concierto de las naciones.

Colombia tiene una pobre presentación en los índices estadísticos internacionales que miden desigualdad, corrupción y violencia; somos sus habitantes quienes definimos o permitimos (lo que viene a ser lo mismo) que así sea; pero la imagen ficticia de un país bueno, culto y alegre oculta el hecho de que son nuestras decisiones cotidianas las que garantizan que así sea. La práctica del arte no ha sido siempre víctima de esta circunstancia, sino -al contrariocon excesiva frecuencia ha sido uno de agentes propiciadores; es el caso de un arte oficial que continúa aliado al expediente de la sintonía con el mundo y de la libertad del artista, como figura ejemplar cuya libertad sería garante de la libertad de la población que, sin embargo, permanece muda.

Si desde una perspectiva generalizadora el carácter fundador de la modernidad es la insatisfacción con el pasado, de la cual deriva una intención de ruptura con la antigüedad, también es cierto que no se crea de la nada; otros pasados deberían acudir en apoyo a la causa, hasta que ya no los necesitáramos. En el arte colombiano ningún pasado es citado; pareciera que una obsesión por la actualidad (internacional) se tradujera en un tiempo homogéneo y vacío, en la imposibilidad de encontrar en esos pasados algún tiempo que pudiera -parafraseando a Benjamin- despertar nuestra endivia, mostrarnos un aire que podríamos haber respirado, hombres con quienes hubiésemos podido hablar; presentarnos muchachas que hubieran podido entregársenos.

\section{NOTAS}

\footnotetext{
1 Son frecuentes, por ejemplo, comentarios de este tipo: "Pocas veces los historiadores colombianos se han dedicado de manera sistemática a estudiar el discurso histórico en nuestro país durante el siglo XIX. Y a pesar de que se han hecho balances y uno que otro texto introductorio, la pregunta por la constitución de nuestra historiografía ha quedado relegada a un segundo plano" (Cardona, 2009, pp. 341-344).

2 Aunque el tema de la modernidad suscita con su sola enunciación toda una serie de discusiones que desbordan este trabajo, es inevitable citarlo. Como se verá, el presente documento se aparta totalmente de la idea común de asimilar, a finales del siglo XIX y comienzos del XX, a un valor (que definiría la calidad de nuestros artistas según se pueda argumentar que son más o menos modernos) y, a finales del siglo XX, a un
} 
antivalor (dada su supuesta superación por la posmodernidad) y, más bien, se afilia a la crítica de Benjamin a la modernidad como una época definida por una serie de tensiones estructurales, arrancándola de la condición de destino ineluctable que el historicismo le atribuía.

3 Más adelante, este canon sería adoptado por Alberto Urdaneta como canon de enseñanza para la Escuela. El concepto de academia, bastante maltratado en el último medio siglo por referencias simplistas y reductoras sin mayores perspectivas históricas o críticas, resulta bastante problemático. Digamos, en aras de la brevedad, que si Groot cita fuentes españolas, Urdaneta (1845-1887), alumno de la Academia Julien y del pintor de temas históricos, citará fuentes francesas. En el proceso de instalación del canon academicista intervendrá también el pintor mexicano Felipe Santiago Gutiérrez (1824-1904), egresado de la Academia de San Carlos, más cercana al modelo español, siendo él mismo alumno del pintor catalán Pelegrín Clavé y, muy probablemente otros tema muy poco estudiado aún- como Pedro Carlos Manrique (1860-1927), quien estudió también en Francia con Epifanio Garay. Igualmente, a esta suma de matices habría que agregar a Cesare Sighinolfi (1833-1903), quien sucedió a Urdaneta en la dirección de la Escuela, formado en su país natal, Italia, y a otros profesores italianos y españoles. Sin embargo, propongo, sin desconocer los matices nacionales que puedan ponerse en juego, como modelo central la academia francesa, porque fue ella la que alcanzó la forma hegemónica en Europa que se irradió a otros contextos geográficos, incluso Italia y España; aunque la academia moderna tiene su origen en Italia, la institución en Francia se convirtió en el lenguaje del despotismo ilustrado, posteriormente del directorio en la Revolución Francesa, de la restauración y de la república, lo que demuestra su fuerza y su capacidad de influir en lugares bastante lejanos.

4 Baste como muestra esta pequeña cita: “El capítulo sexto se ocupa de los sucesos que afectaron la vida de Groot después de la publicación de la Historia eclesiástica y civil: dedicó sus esfuerzo a refutar al protestantismo, a sostener polémicas (...) a defender la literalidad de la Biblia y a impugnar a Marx y Nietzsche (...)" (Cardona, 2009).

5 Ver, al respecto, el detallado estudio Vásquez Ceballos y la crítica de arte en Colombia (Montoya y Gutiérrez, 2008). Groot cita en su obra a Mengs (Anton Rafael 1728-1779, nacido en Alemania, fue uno de los más importantes ideólogos de la academia española), a Palomino (Antonio Palomino de Castro y Velasco, 16551726, autor de El museo pictórico, y escala óptica, 1795), la Biblia y el Museo universal de pintura y escultura, en el que nos detenemos un momento en este artículo (Joaquín Verdaguer, 1840).

6 "Y fue, en realidad, un trabajo genial (...) contemplado por todos con asombro y por nadie comprendido, inmediatamente después de este acontecimiento, se alzó Marx con una exposición breve, epigramática, en que se explicaba en su concatenación interna toda la marcha de la historia de Francia desde las jornadas de Febrero, se reducía el milagro del 2 de diciembre a un resultado natural y necesario de esta concatenación (...) Fue precisamente Marx el primero que descubrió la gran ley que rige la marcha de la historia, la ley según la cual todas las luchas históricas, ya se desarrollen en el terreno político, religioso, filosófico, ya en otro terreno ideológico cualquiera, no son, en realidad, más que la expresión más o menos clara de luchas entre clases sociales, y que la existencia y por tanto también los choques de estas clases, están condicionados, a su vez, por el grado de desarrollo de su situación económica, por el modo de su producción y de su intercambio, condicionado por ésta. Dicha ley (...) tiene para la historia la misma importancia que la ley de la transformación de la energía para las Ciencias Naturales", dice Engels en el prólogo a la tercera edición alemana del Dieciocho Brumario, "treinta y tres años después de publicada la primera" (Marx, s.f., p. 95).

7 En la descripción que hace Groot del proceso de este libro, transcribe la copia de la partida de bautismo de Vásquez, fechada el 30 de octubre de 1850, lo que nos indica que estaba trabajando en su investigación al menos desde ese año. Según él mismo, éste hallazgo es el valor fundamental de la obra. Este concepto aún se repite, y evidentemente en su momento tenía una enorme importancia estratégica, pues confirmaba que Vásquez era nativo de América, lo que producía un gran efecto en la construcción de un discurso nacional y proveía un mito fundacional a la historia del arte colombiano; sin embargo, esta declaración parece haber opacado el importante hecho que ya se ha mencionado: que situaba como base legitimadora de la calidad del artista su validez dentro del canon academicista.

8 Sin embargo, dice Groot más adelante "Historia de la provincia de San Antonio del Nuevo Reino de Granada del órden de predicadores por el padre M. F. Alonso de Zamora: (...) I atiéndase que el padre Zamora escribia su obra por los años de 1682; es decir, viviendo Vásquez. Sirva esta noticia para los que dicen que las pinturas de Vasquez fueron traidas de Europa i que no existió tal pintor en Santafé" (1859, pp. 58-59). Esta historia se publicó en Barcelona en 1701, en el prólogo a la edición publicada por el Ministerio de Educación en 1945 (Zamora, 1945).

9 Así empieza el primero de los Nueve libros de la historia, Clío, de Heródoto de Halicarnaso. 
10 Aparecen moderno, moderna como adjetivos en el sentido de hechos contemporáneos al autor, aunque se remite a la "edad moderna". Sin embargo, también se relacionan en algunos momentos con un cambio específico en la sensibilidad y en la naturaleza de algunos fenómenos. Siguiendo un rápido recorrido por algunas de las instancias de la Enciclopedia moderna, hay una tendencia generalizada a diferenciar el mundo antiguo y el moderno, lo que en cuestiones de arte se concreta en la oposición de "escuelas antigua y moderna, ó sea clásica y romántica" (Mellado, 1851, p. 475) (la cursiva no es del original).

11 Que, significativamente, parece muy representada en el ámbito escolar. Asimismo, no importa lo que se haya dicho, no importan las críticas y análisis de Benjamin o de la Escuela de Frankfurt, siglo y medio después, las exposiciones - llámense mundiales, internacionales o universales, como la próxima del 2015 en Milángozan de cabal salud; la historia universal también, véase, por ejemplo, la Concepción moderna de la historia universal de Mauro Torres (1997), cuya ausencia de rigor historiográfico y la prolongación de una polaridad imposible de sostener entre civilización y barbarie le quitaría todo interés si no fuera escrita por un miembro de la Academia Colombiana de Historia y la Real Academia Española de Historia.

12 Jacques Benigne Bossuet (1627-1704), preceptor de Luis XIV, es un clérigo defensor de la monarquía del absolutismo y del origen divino del poder del rey. Dice Bossuet en el "Discurso sobre la historia universal" texto que se reproduce en el tomo I, página 1 de Los héroes y las grandezas de la tierra, dirigido al Delfín Luis de Francia en 1861: “Este libro ofrece á V. A. un grande espectáculo. Ve en él V. A. desenvolverse todos los siglos, por decirlo así, en pocas horas delante de sus ojos: mira como se suceden los imperios unos á otros, y como se sostiene igualmente la religión en sus diferentes estados desde el principio del mundo hasta nuestros días.

La continuación, pues, de estas dos cosas, quiero decir, de la religión y de los imperios, es la que debe V. A. imprimir en la memoria; y como la religión y el gobierno político son los dos polos en que giran las cosas humanas, el ver todo lo que conduce á ellas reducido á un epílogo breve, y descubrir por este medio todo su orden y continuación, es comprender todo lo grande que hay entre los hombres, y tener (por decirlo así) el hilo de todos los sucesos del universo" (1856). No sobra recordar que la primera parte de la historia que referimos empieza con la creación de Adán.

13 Bossuet es citado, por ejemplo, en documentos tan importantes como: "Historia de nuestra revolución", artículo publicado originalmente en el Diario Político de Santafé de Bogotá. No. 2 (29 agosto 1810).

14 Capítulo IX del Quijote. Justamente célebre, particularmente subrayado por Jorge Luis Borges en el cuento "Pierre Menard, autor del Quijote" (Ficciones, 1944), este fragmento aparece en momentos en que, efectivamente, es Cervantes quien habla, pues la novela -que inaugura la literatura moderna española- pone en escena el recurso de la historia dentro de la historia: Cervantes asegura no ser el autor, sino que ha recogido el texto de un autor árabe, Cide Hamete Benengeli, y en el capítulo IX habla del hallazgo de una parte de este texto cuya pérdida habría dejado inconclusa la narración.

15 La mejor y más crítica caracterización de esta modernidad laberíntica en la que las imágenes extraviadas del tiempo se decantan en un ambiento rarificado y estático, fantasmagórico, en el que se diluye la experiencia, es la de Walter Benjamin. Particularmente el ensayo "París, capital del siglo XIX" nos lanza sin concesiones esta imagen dura "El objeto de este libro es una ilusión que fue expresada por Schopenhauer en la fórmula de que para captar la esencia de la historia basta con comparar a Heródoto con la Presse du matin. Es la expresión de la sensación de vértigo característica de la concepción de que el siglo pasado se hacía de la historia. Corresponde a un punto de vista que integra el curso del mundo en una serie ilimitada de hechos coagulados en forma de cosas. El residuo característico de esta concepción es lo que se ha llamado 'la Historia de la Civilización' que hace el inventario de las formas de vida y de las creaciones de la humanidad punto por punto. Las riquezas así coleccionadas en el erario de la civilización aparecen en adelante identificadas para siempre. Esta concepción hace poco caso del hecho de que ellas no solamente deben su existencia, sino incluso su transmisión, a un esfuerzo constante de la sociedad, un esfuerzo por el que esas riquezas se encuentran por añadidura extrañamente alteradas. Nuestra investigación se propone mostrar cómo a consecuencia de esta representación cosista de la civilización, las formas de vida nuevas y las nuevas creaciones de base económica y técnica que le debemos al siglo pasado entran en el universo de una fantasmagoría. Esas creaciones sufren esta 'iluminación' no sólo de manera teórica, mediante una transposición ideológica, sino en la inmediatez de la presencia sensible. Se manifiestan como fantasmagorías" (Benjamin, 2007, p. 50).

16 Fenómeno relacionado con lo que en otros lugares he llamado "la sociedad educativa" de lo que verá un ejemplo enseguida con la difusión de obras plásticas a través del "grabado de contorno". En dicha sociedad la licitud de los fines -a saber, relacionados con su crecimiento mental, espiritual y, por lo tanto, materiallegitima en la práctica las autoridades y los modelos que deben ser impuestos al conjunto de la sociedad, particularmente a los lejanos de esos círculos de poder. 
17 José Manuel Matilla (Valladolid, 1962, jefe del Departamento de Dibujos y Estampas del Museo Nacional del Prado) nos informa sobre los procedimientos de reproducción de pinturas en grabado que desembocarán en publicaciones como el Museo universal: "Tendremos que esperar hasta mediados del siglo XVII para encontrar un proyecto en el que la estampa desempeñe el papel de reproducir de forma más o menos sistemática una colección de pintura" (2000, pp. 75-122). El texto explica el uso propagandístico del grabado "La publicidad o pedagogía del Barroco, fundamentada en el revestimiento de las ideas mediante atractivas imágenes que sorprendían y cautivaban al espectador, buscaba persuadir a este creando un estado receptivo que permitiese una mejor asimilación de los contenidos. Esta fue precisamente la función principal de la estampa: ayudar a configurar mentalidades y agruparlas ideológicamente".

En relación con el caso que nos ocupa, Matilla desarrolla el tema de la técnica que, al mismo tiempo que informa sobre la obra pictórica, ejerce un filtro que selecciona lo que cabe en un modelo determinado: el neoclasicismo: "Del mismo modo que los artistas buscaron en el aguafuerte el método para acometer su trabajo de forma autónoma, cuando los editores y escritores de comienzos del siglo XIX desearon ilustrar sus publicaciones encontraron en él uno de los medios más idóneos si lo que buscaban era imágenes de calidad. Las primeras publicaciones en las que se reproducen las principales colecciones de pintura europeas, dirigidas a un público culto pero no necesariamente rico, se sirvieron del aguafuerte para reproducir las obras, pero lo hicieron no a través de la técnica propia de artistas como la desarrollada por Goya, sino a través del grabado de contorno, a medio camino entre el clasicismo formal del grabado en talla dulce y la rapidez de ejecución del aguafuerte. Esta clase de grabado, en la que básicamente se representa tan sólo el contorno de las figuras, hunde sus raíces en la estética del Neoclasicismo, en la que "el alma considera como más bello aquello de lo que puede hacerse una idea en el menor lapso de tiempo", como escribía Frans Hemsterhuis en 1769 para justificar la superioridad estética del dibujo de contorno. Inicialmente este lenguaje tiene su razón de ser en la representación de la Antigüedad clásica, del paradigma clásico y tendrá ramificaciones que llegarán hasta bien entrado el siglo XIX de la mano de las academias de bellas artes, principales difusoras del modelo clásico y de sus formas de representación, que lo aplicarán no sólo a la divulgación de las obras de la Antigüedad y de aquellas concebidas con ese lenguaje, sino también a la difusión de las obras de otros periodos históricos, no necesariamente clasicistas" (Matilla, 2000, pp. 75-122).

18 Este tema nos ofrece otra perspectiva de la reacción vanguardista contra la academia, que un gran sector de la historiografía tradicional del arte reduce a una confrontación de estilos. Al historicismo de la academia, las vanguardias, con su autoconciencia tautológica de la obra de arte que solamente habla de sí misma, opone la historicidad de la misma.

19 "Los hombres hacen su propia historia, pero no la hacen a su libre arbitrio, bajo circunstancias elegidas por ellos mismos, sino bajo aquellas circunstancias con que se encuentran directamente, que existen y les han sido legadas por el pasado. La tradición de todas las generaciones muertas oprime como una pesadilla el cerebro de los vivos. Y cundo éstos aparentan dedicarse precisamente a transformarse y a transformar las cosas, a crear algo nunca visto, en estas épocas de crisis revolucionarias es precisamente cuando conjuran temerosos en su auxilio los espíritus del pasado, toman prestados sus nombres, sus consignas de guerra, su ropaje, para, con este disfraz de vejez venerable y este lenguaje prestado, representar de nuevo la escena de la historia universal (...) Es como el principiante que ha aprendido un idioma nuevo: lo traduce siempre a su idioma nativo, pero sólo se asimila el espíritu del nuevo idioma y sólo es capaz de expresarse libremente en él cuando se mueve dentro de él sin reminiscencias y olvida en él su lenguaje natal" (Marx, s.f., p. 95).

20 Benjamin nos propone una serie de imágenes perturbadoras en la que una época sueña la siguiente; lo que evidencia la potencia anunciadora de estas imágenes, pero también su radical incapacidad de imaginar lo nuevo sin invocar las visiones del pasado, consecuencia de lo cual, este futuro inevitablemente tiene la apariencia de la ruina y un mundo físico limitado, laberíntico (como un laberinto de espejos), claustrofóbico y repetitivo hasta la eternidad. Es un mundo de sueño, del que paradójicamente solamente podrá escapar la humanidad poniendo al servicio del despertar los elementos del propio sueño.

21 La expresión se justifica, porque -aunque no lo profundicemos en este documento- no podemos olvidar en ningún momento que éste es un mundo, una historia, unas mentalidades y unos procesos definidamente masculinos.

22 Sobre el tema, está en curso de publicación la ponencia "Corrigendo el pasado: Luis Alberto Acuña, artista historiador" presentada en el III Encuentro Nacional de Estética y Filosofía del Arte, Universidad Nacional, Medellín, mayo del 2013.

23 De las cuales, hasta donde llegan mis indagaciones, la más renovadora fue la reforma Mockus-Páramo de la Universidad Nacional, que incluyó al programa de Artes Plásticas. 


\section{REFERENCIAS}

Benjamin, Walter. "París, capital del siglo XIX". En Libro de los pasajes, Tiedemann, Rolf (ed). Madrid: Akal, 2007. 50.

Cantú, César. Historia universal, traducida directamente del italiano con arreglo á la sétima edición de Turin, anotada por D. Nemesio Fernandez Cuesta. I tomo. Madrid: Gaspar y Roig, 1854.

Cardona, Patricia. “Mejía, Sergio. El pasado como refugio y esperanza. La historia eclesiástica y civil de José María Groot (1800-1878). Bogotá: Instituto Caro y Cuervo, [2009]". Historia Crítica. [En línea] Edición especial (noviembre 2009): 341-344. http://historiacritica.iniandes. edu.co/view.php/634/view.php (Acceso: 1 de Julio de 2011).

Groot, José Manuel. Noticia biográfica de Gregorio Vasquez Arce i Ceballos: Pintor granadino del siglo XVII: con la descripcion de algunos cuadros suyos en que mas se da a conocer el merito del artista. Santa Fé de Bogotá: Imprenta de Francisco Tórres Amaya, 1859. [En línea] Universidad de los andes, https://ada.uniandes.edu.co/site/archivos/1744.pdf. (Acceso: 15 de enero de 2014).

Groot, José Manuel. "Cuadros rústicos de costumbres granadinas." En José Manuel Groot: (1800-1878), ed. B. González y B. Gonzalez. [En línea]. Bogotá: Banco de la República, Departamento Editorial, 1991. http://www.banrepcultural.org/blaavirtual/todaslasartes/groot/ groot0.htm (Acceso: 1 julio del 2011).

Heródoto de Halicarnaso, "Clío", Nueve libros de la historia. [En línea], http://www.antorcha.net/ biblioteca_virtual/historia/herodoto/1.html (Acceso: 10 de enero de 2014).

Quintero Montiel, Inés y Martínez Garnica, Armando (eds). “Actas de formación de juntas y declaraciones de independencia (1809-1822)." Universidad Industrial de Santander. [En línea] https://www.uis.edu.co/webUIS/es/bicentenario/documentos/BICENTENARIO_ACTAS_ TOMO\%20I.pdf (Acceso: 1 de julio de 2013).

Marx, Karl. "El dieciocho brumario de Luis Bonaparte". En Obras escogidas. Moscú: Editorial Progreso, 1976. 408-505.

Matilla, José Manuel. (2000). “De la propaganda real a la interpretación del artista. La reproducción de la pintura de Velázquez a través de las técnicas tradicionales del arte gráfico". En Velásquez en blanco y negro. La pintura de Velásquez en el grabado de sus contemporáneos. [En línea]. Madrid: Fundación Amigos del Museo del Prado, 2000. 75-122. http://cvc.cervantes.es/artes/velazquez/reproduccion.htm (Acceso: 1 julio del 2011).

Mellado, Francisco de Paula. Enciclopedia Moderna: Diccionario Universal de Literatura, Ciencias, Artes, Agricultura, Industria y Comercio, Volumen 1, Madrid: Establecimiento Tipográfico de Mellado, 1851.

Montoya, Armando y Gutiérrez, Alba Cecilia. Vásquez Ceballos y la crítica de arte en Colombia. Medellín: Editorial Universidad de Antioquia, 2008.

Ortiz de la Vega, Manuel. Los héroes y las grandezas de la tierra - anales del mundo, formación, revoluciones y guerras de todos los imperios, desde la creación hasta nuestros días. Tomo I, Madrid-Barcelona: Librería de José Cuesta-Administración de la imprenta de Cervantes, 1856.

Torres, Mauro, Concepción Moderna De La Historia - El Remoto Origen De La Historia Masculina, Tercer Mundo, Bogotá, 1997.

Vasari, Giorgio. Las vidas de los más excelentes pintores, escultores y arquitectos, escritas por Giorgio Vasari. México: Universidad Nacional Autónoma de México, 1996.

Verdaguer, Joaquín. Museo universal de pintura y de escultura y galeria europea de las artes y de la historia - adornada con 36 hermosas laminas grabadas por el célebre Reveil. Barcelona: Imprenta Joaquín Verdaguer, 1840.

Zamora, Alonso de. Vol. 1 de Historia de la provincia de San Antonino del Nuevo Reino de Granada ed. B. P. Colombiana. Bogotá: ABC, 1945. 
Cómo citar este artículo:

Huertas, Miguel. "Colombia bajo el imperio de la historia universal. Notas sobre el olvido". Cuadernos de Música, Artes Visuales y Artes Escénicas, 9 (1), 15-34, 2014, http://dx.doi. org/10.11144/Javeriana.MAVAE9-1.cbih 